\title{
Integrated Modelling of Microstructure Evolution and Mechanical Properties Prediction for Q\&P Hot Stamping Process of Ultra-High Strength Steel
}

\author{
Yang Chen ${ }^{1,2}$, Huizhen Zhang ${ }^{1,2}$, Johnston Jackie Tang ${ }^{1,2}$, Xianhong Han ${ }^{1,2^{*}}$ and Zhenshan Cui ${ }^{1,2}$
}

\begin{abstract}
High strength steel products with good ductility can be produced via Q\&P hot stamping process, while the phase transformation of the process is more complicated than common hot stamping since two-step quenching and one-step carbon partitioning processes are involved. In this study, an integrated model of microstructure evolution relating to Q\&P hot stamping was presented with a persuasively predicted results of mechanical properties. The transformation of diffusional phase and non-diffusional phase, including original austenite grain size individually, were considered, as well as the carbon partitioning process which affects the secondary martensite transformation temperature and the subsequent phase transformations. Afterwards, the mechanical properties including hardness, strength, and elongation were calculated through a series of theoretical and empirical models in accordance with phase contents. Especially, a modified elongation prediction model was generated ultimately with higher accuracy than the existed Mileiko's model. In the end, the unified model was applied to simulate the Q\&P hot stamping process of a U-cup part based on the finite element software LS-DYNA, where the calculated outputs were coincident with the measured consequences.
\end{abstract}

Keywords: Q\&P hot stamping, Phase transformation model, Microstructure evolution, Product properties prediction

\section{Introduction}

Consumption of non-renewable petroleum, traffic safety, and air pollution have been becoming a serious problem along with the development of auto industry. Song et al. [1] studied that weight reduction of body-in-white can significantly lower the entire weight, resulting in fuel efficiency. The ultra-high strength steel manufactured via hot stamping has become one of the primary materials to build light-weighting vehicles. According to Bok et al. [2], a blank was heated to the austenitizing temperature (above the $\mathrm{Ae}_{3}$ ) and kept a few minutes before being

\footnotetext{
*Correspondence: hanxh@sjtu.edu.cn

1 Institute of Forming Technology \& Equipment, School of Materials Science and Engineering, Shanghai Jiao Tong University,

Shanghai 200030, China

Full list of author information is available at the end of the article
}

transferred onto a tool for further forming and quenching. The tensile strength of the final product would reach approximately $1500 \mathrm{MPa}$ due to almost full transition of martensite.

Lath martensite is the essential microstructure of the parts made by hot stamping process, providing the specimens with high strength but low plasticity. In general, the elongation of hot-stamped sample is less than 7\%, which leads to unexpectedly comprehensive mechanical properties. Q\&P heat treatment technology was proposed by Speer et al. [3] at initial. The duplex phase involving martensite and austenite is the final microstructure of a product after Q\&P heat treatment, in which the plasticity and toughness has been improved. Liu et al. [4] proposed Q\&P hot stamping process which combined Q\&P heat treatment with hot stamping. The consequence of 
thermal simulation indicated that the product's plasticity was significantly revised by Q\&P hot stamping, while the strength loss was relatively negligible. Han et al. [5] designed and manufactured a corresponding mold to produce some U-cap parts by Q\&P hot stamping where three types of steel were studied for the availability of Q\&P hot stamping, respectively.

Investigating microstructure evolution is worthwhile, because the microstructure transformation has a great influence on the final mechanical properties of a product manufactured through Q\&P hot stamping process. Therefore, the development of the prediction models of mechanical properties, and simulation are mandatory in the operation of the process and optimization of parameters.

Microstructure evolution models have become a rising research field to investigators who contribute in hot forming technology. Regarding to diffusional phase transformation, Kirkaldy and Venugopalan [6] proposed the $\mathrm{K}-\mathrm{V}$ model for microstructure prediction. Li et al. [7] presented a modified model where the TTT curve in the $\mathrm{K}-\mathrm{V}$ model was substituted by CCT curve, and the new model was known as Li model. Åkerström and Oldenburg [8] generated an A-O model that is based on the $\mathrm{K}-\mathrm{V}$ model, where the effect of boron element was considered and included. As for non-diffusional phase transformation, Koistinen and Marburger [9] created the K-M model, which became the fundamental model in studying martensitic transformation. The impacts of temperature change and austenite grain size were further involved in Lee model proposed by Lee et al. [10], and the model had predicted the deformation of a cylindrical sample during quenching process successfully. In addition, Zhu et al. [11] proposed a model to describe the carbon diffusion and interface migration during the carbon partitioning process. Wang et al. [12] coupled the micro-scale carbon diffusion and interface migration laws into macro-scale thermomechanical coupling simulation, performed a multi-physics, multi-scale, multi-phase coupling simulation for Q\&P hot stamping, and studied the microstructure evolution during two-stage Q\&P process [13].

The research on the relationship between microstructure and mechanical properties is relatively deficient compared with the aforementioned studies, and almost concentrated on hardness prediction. For example, Lee et al. [14] studied the decomposition process of austenite among 1045 steel through Li model, and the accuracy of the prediction was verified through a hardness experiment. Zhu et al. [15] predicted the microstructure evolution of hot-stamping components through $\mathrm{K}-\mathrm{V}$, and $\mathrm{K}-\mathrm{M}$ model, and observed the changing tendency of hardness and strength along with cooling rate via experimental results. Hamelin et al. [16] predicted the ferrite distribution and hardness by the Li model during a welding process. Cui et al. [17] investigated the austenite decomposition process of the spheroidized bearing steel by combining the thermodynamics and kinetics simulation, the hardness of the product was predicted as well. Yasuhiro et al. [18] predicted the phase transformation and hardness of spot welded tailored blank in hot stamping, and the calculated results were consistent with experimental values. Mori et al. [19] summarized the research on properties prediction, and offered some instances of the prediction of product property, i.e., hardness prediction.

According to previous researches and utilizations of phase transformation models and properties prediction, the following issues should be concerned: (1) The phase transformation models of hot stamping were only applied within general hot stamping, but occasionally used in the Q\&P hot stamping. (2) The current predictions of the mechanical properties of hot-stamped materials are based on the measurement of microstructure content by observation, and the predicted field is limited to the prediction of hardness values, and rarely involves tensile strength and elongation.

In this work, a complete procedure of microstructure evolution and properties prediction integrated model for Q\&P hot stamping process was established, in which combined with the constrained carbon para equilibrium model (CCE model). All introduced models were incorporated in the finite element software LS-DYNA, and the thermal simulation of Q\&P hot stamping and the experiments of U-cap parts were operated. Conclusively, the accuracy of the integrated models was persuasive by comparing to experimental results.

\section{Integrated Model for Phase Transformation and Mechanical Properties Prediction \\ 2.1 Description of Q\&P Hot Stamping Process}

Q\&P hot stamping is an advanced technology combining of hot stamping and Q\&P heat treatment. In order to gain a whole austenite microstructure, the blank is heated to exceed the temperature of $A_{3}$ before transferring onto a tool for quenching and forming. The specimen is being held at a carbon partitioning temperature $\left(P_{T}\right)$ after approach a designated temperature spot between $M_{s}$ and $M_{f}$, which is known as the quenching temperature $\left(Q_{T}\right)$. Finally, lath martensite and retained austenite are collected at the end of cooling, i.e., the temperature of the sheet has equaled to the room temperature. Moreover, one-step Q\&P hot stamping indicates the carbon partitioning temperature $P_{T}$ and the quenching temperature $Q_{T}$ are identical. Meanwhile, the temperature of carbon diffusion $P_{T}$ is adjusted to be higher than $Q_{T}$ in two-step Q\&P 
process. The prediction of microstructure evolution and mechanical properties were achieved by one-step Q\&P hot stamping essentially in this study. The schematic illustration of the one-step Q\&P hot stamping proposed by Han et al. [5] is shown in Figure 1 .

Q\&P hot stamping consists of two quenching processes and one carbon diffusion process. The transformations of ferrite, pearlite, bainite and martensite are conducted regularly in the first quenching stage, until the carbon partitioning temperature is approached. Carbon atoms are transferred from the martensite into the retained austenite during dissemination, resulting in the reduction of the second martensite transformation temperature $\left(M_{r s}\right)$ since the carbon content within austenite is adequate. Additionally, unconverted austenite is shifted into secondary martensite while others remain as retained austenite if the $M_{r s}$ is higher than the room temperature. Dissimilarly, the rest of austenite is unaffected, i.e., no transformation happened after subsequent quenching process if the $M_{r s}$ is lower than the room temperature. Anyway, both diffusional and non-diffusional phase transitions and carbon diffusion process during Q\&P hot stamping require corresponding models of description.

\subsection{Integrated Model for Phase Transformation}

\subsubsection{Diffusional Phase Transition Model}

The $\mathrm{Li}$ model [7] was developed and modified in accordance with K-V model [6], which was qualified to predict the diffusional phase transitions, i.e., ferrite, pearlite and bainite transitions. The TTT curve of the $\mathrm{K}-\mathrm{V}$ model was substituted by CCT curve in Li model which is capable for continuous-cooling condition

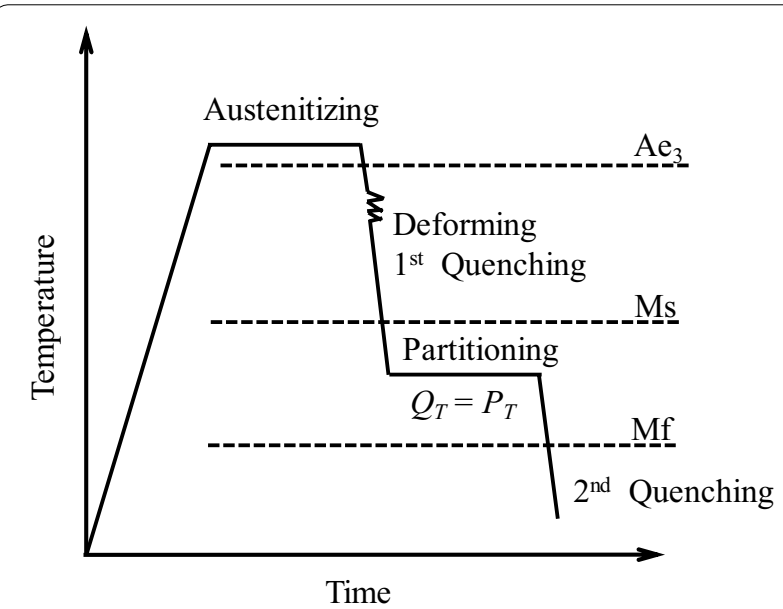

Figure 1 Schematic illustration of the one-step Q\&P hot stamping process happened in practical manufacture. Li model can be expressed as:

$$
\frac{\mathrm{d} X}{\mathrm{~d} t}=\frac{f(G, T)}{f(\operatorname{Comp})} f(X),
$$

where $X$ is the phase fraction of ferrite, pearlite and bainite, $f(G, T)$ represents the influence of the austenite grain size and the temperature on the phase transformation, $f(C o m p)$ stands for the effect of the material element on phase transformation, $f(G, T)$ and $f(C o m p)$ are various for different phase. $f(X)$ represents the $\mathrm{S}$ curve of phase transformation fraction, which is defined as:

$$
f(X)=X^{0.4(1-X)}(1-X)^{0.4 X} .
$$

\subsubsection{Non-diffusional Phase Transition Model}

Lee model [10] is applied to predict martensitic transformation during both two quenching processes, where the influence of austenite grain size and temperature changing are involved to improve prediction accuracy. The specific expression of the Lee model is expressed by:

$$
\frac{\mathrm{d} X_{m}}{\mathrm{~d} T}=K \cdot X_{m}^{a}\left(1-X_{m}\right)^{b},
$$

where $X_{m}$ is the martensite content, and $a, b$, and $K$ can be calculated individually by:

$$
\begin{aligned}
& a=0.420-0.246 C+0.359 C^{2}, \\
& b=1.320+1.576 C+1.933 C^{2}, \\
& K=\frac{G^{0.240} \cdot\left(M_{s}-T\right)^{0.191}}{9.017+62.88 C+9.27 N i-1.08 C r+25.76 M o},
\end{aligned}
$$

where $M_{s}$ can be expressed by:

$$
\begin{aligned}
M_{s}(K)= & 402-797 \mathrm{C}+14.4 \mathrm{Mn}+15.3 \mathrm{Si} \\
& -31.1 \mathrm{Ni}+345.6 \mathrm{Cr}+434.6 \mathrm{Mo} \\
& +(59.6 \mathrm{C}+3.8 \mathrm{Ni}-41 \mathrm{Cr}-53.8 \mathrm{Mo}) \mathrm{G} \\
& +273.15
\end{aligned}
$$

where the element symbols stand for mass fractions.

\subsubsection{Carbon Diffusion Model}

The constrained carbon para equilibrium model (CCE model) was proposed by Speer et al. [20] for investigating the carbon diffusional dynamics within carbon partitioning. The CCE model is expressed by: 


$$
X_{C}^{\gamma}=X_{C}^{a} \exp \left(\frac{76789-43.8 T-(169105-120.4 T) X_{C}^{\gamma}}{R \cdot T}\right) .
$$

The carbon contents within austenite phase and martensite phase were equal to the total carbon content $X_{C}$ within steel before carbon partitioning. After the initial quenching, austenite mole fraction $f_{i}^{\gamma}$ and the martensite mole fraction $f_{i}^{\alpha}$ could be computed. The austenite mole fraction and carbon content were updated to $f_{C C E}^{\gamma}$ and $X_{C_{C C E}}^{\gamma}$, respectively, when the carbon partitioning was done. According to the conservation of iron atoms without movement at interface, the following equation can be derived:

$$
f_{C C E}^{\gamma}\left(1-X_{C_{C C E}}^{\gamma}\right)=f_{i}^{\gamma}\left(1-X_{C}\right) .
$$

The total content of carbon is constant, which can be expressed by:

$$
f_{C C E}^{a} X_{C_{C C E}}^{a}+f_{C C E}^{\gamma} X_{C_{C C E}}^{\gamma}=X_{C}
$$

Additionally, the ultimate mole fraction of the two phases is constant as well:

$$
f_{C C E}^{a}+f_{C C E}^{\gamma}=1,
$$

where $X_{C}^{\gamma}$ and $X_{C}^{a}$ are the carbon mole fraction in austenite $\gamma$ and martensite $a$, respectively. $X_{C}$ is the total carbon content, $R$ is gas constant $8.314 \mathrm{~J} /(\mathrm{mol} \cdot \mathrm{K}), T$ is the absolute temperature, $f_{i}^{\gamma}$ is the austenite mole fraction after the initial quenching of a steel blank. $f_{C C E}^{a}$ and $X_{C_{C C E}}^{a}$ are the martensite mole fraction, and carbon content after the carbon partitioning, individually. $f_{C C E}^{\gamma}$ and $X_{C_{C C E}}^{\gamma}$ are the austenite mole fraction and carbon content after carbon partitioning, independently. The carbon contents will be identical after partitioning is finished, i.e., $X_{C}^{\gamma}=X_{C_{C C E}}^{\gamma}, X_{C}^{a}=X_{C_{C C E}}^{a}$.

\subsubsection{Integrated Model for Phase Transformation}

In this work, the Li model [7] and Lee model [10] were utilized to describe the transitions of diffusional phase and non-diffusional phase in the first quenching processes to obtain the contents of martensite, bainite, ferrite, pearlite, and unconverted austenite. Then, the CCE model [20] was employed to describe the diffusional dynamics of carbon in the carbon partitioning process, and the carbon contents of martensite and austenite were calculated. Based on this, the $M_{r s}$ point for the second quenching process was also obtained. If $M_{r s}$ was higher than room temperature, the Lee model would be used to describe the second martensite transformation process. Otherwise, the unconverted austenite would be reserved to room temperature. Thus, the phase transformation and the final phase contents were all predicted accurately.

Besides aforementioned models, other alternative models, such as $\mathrm{K}-\mathrm{V}$ model, A-O model that including the influence of boron are also available for diffusional phase transitions. In contrast, the K-M model is extensively utilized in the prediction of non-diffusional phase transitions. The calculated results of some models will be compared and analyzed in the next part.

\subsection{Mechanical Properties Prediction Models}

Regarding a target material, its mechanical properties are primarily depended on the composition of each phase, i.e., the mechanical properties can be predicted based on the accurate content of different phases. A combined rule of calculating the hardness, and an empirical model for calculating the strength are discussed in this section. Regarding to the elongation prediction, a modified model involving the effect of bainite has been created on the basic of the two-phase hybrid representation model.

\subsubsection{Hardness Combined Rule}

The hardness combined rule is implemented to compute the hardness of an output after Q\&P hot stamping. The overall objective function is expressed by Li et al. [7]:

$$
H V=X_{M} H V_{M}+X_{B} H V_{B}+\left(X_{F}+X_{P}\right) H V_{F+P},
$$

where $H V$ represents the Vickers hardness, $H V_{M}, H V_{B}$, $H V_{F+P}$ represent martensite hardness, bainite hardness, and ferrite \& pearlite mixed phase hardness. The magnitude of hardness of each phase relates to the cooling rate and the content of elements. The calculation formulas are expressed by Li et al. [7].

Martensite hardness:

$$
\begin{aligned}
H V_{M}= & 127+949 C+27 S i+11 M n \\
& +8 N i+16 C r+21 \log V r .
\end{aligned}
$$

Bainite hardness:

$$
\begin{aligned}
H V_{B}= & -323+185 \mathrm{C}+330 \mathrm{Si}+153 \mathrm{Mn} \\
& +65 \mathrm{Ni}+144 \mathrm{Cr}+191 \mathrm{Mo} \\
& +(89+53 \mathrm{C}-55 \mathrm{Si}-22 \mathrm{Mn}-10 \mathrm{Ni} \\
& -20 \mathrm{Cr}-33 \mathrm{Mo}) \log \mathrm{Vr} .
\end{aligned}
$$

Ferrite and pearlite mixture hardness:

$$
\begin{aligned}
H V_{F+P}= & 42+223 C+53 S i+30 M n \\
& +12.6 N i+7 C r+19 M o \\
& +(10-19 S i+4 N i+8 C r+130 V) \log V r,
\end{aligned}
$$

where $V r$ is the cooling rate $\left({ }^{\circ} \mathrm{C} / \mathrm{h}\right)$ at $700{ }^{\circ} \mathrm{C}$. 


\subsubsection{Strength Prediction Model}

Cui's empirical formula is able to output the material strength after Q\&P hot stamping. Cui et al. [21] performed a plenty of tensile, and hardness tests on boron steel after hot stamping, where the empirical formula for strength and hardness is concluded as follows:

$$
y=y_{0}+a e^{x / b},
$$

where $y_{0}=226.05108, a=272.0922, b=29.15449, x$ is Rockwell hardness. The Vickers hardness predicted by hardness combined rule can be converted into Rockwell hardness according to GB/T 1172-1999. In the meantime, the magnitude of strength can be computed by Eq. (16).

\subsubsection{Elongation Prediction Model and Its Modified Model}

Matlock and Speer [22] used the Mileiko's two-phase hybrid representation model presented by Mileiko [23] to predict the tensile strength and elongation of mixed martensitic and austenitic phase. The Mileiko's model assumes that both phases are capable to process plastic deformation, and the strains are equally consistent at every time segment. The relationship between stress and strain of the hybrid phases is expressed by:

$$
\begin{aligned}
S_{\text {all }}= & X_{M} S_{M}+X_{A} S_{A} \\
= & \left(1-X_{A}\right) S_{M}^{*}\left(\frac{\varepsilon}{\varepsilon_{M}^{*}}\right)^{\varepsilon_{M}^{*}} \exp \left(\varepsilon_{M}^{*}-\varepsilon\right) \\
& +X_{A} S_{A}^{*}\left(\frac{\varepsilon}{\varepsilon_{A}^{*}}\right)^{\varepsilon_{A}^{*}} \exp \left(\varepsilon_{A}^{*}-\varepsilon\right),
\end{aligned}
$$

where $S_{\text {all }}$ is the total stress of the hybrid phases (nominal stress), $\varepsilon$ is true strain, $S_{M}$ and $S_{A}$ are the martensite stress and austenite stress, respectively. $X_{M}$ and $X_{A}$ are the volume fraction of the martensite and austenite, respectively. $S_{M}^{*}$ and $\varepsilon_{M}^{*}$ are the tensile strength and elongation of martensite, and $S_{A}^{*}$ and $\varepsilon_{A}^{*}$ are the tensile strength and elongation of austenite individually.

Besides some austenite remains, the content of bainite is noticeable after performing a metallographic structure observation and various phase contents determination of Q\&P thermal simulation samples in this paper. Kumar et al. [24] have confirmed that the elongation and toughness can be improved by bainite structure, especially upper bainite. Hence, a modified model of elongation prediction is made depending on the two-phase hybrid representation model and the effect of bainite, which can be expressed as:

$$
\begin{aligned}
S_{\text {all }}= & X_{M} S_{M}+X_{A} S_{A}+X_{B} S_{B} \\
= & X_{M} S_{M}^{*}\left(\frac{\varepsilon}{\varepsilon_{M}^{*}}\right)^{\varepsilon_{M}^{*}} \exp \left(\varepsilon_{M}^{*}-\varepsilon\right)+X_{A} S_{A}^{*}\left(\frac{\varepsilon}{\varepsilon_{A}^{*}}\right)^{\varepsilon_{A}^{*}} \\
& \exp \left(\varepsilon_{A}^{*}-\varepsilon\right)+X_{B} S_{B}^{*}\left(\frac{\varepsilon}{\varepsilon_{B}^{*}}\right)^{\varepsilon_{B}^{*}} \exp \left(\varepsilon_{B}^{*}-\varepsilon\right) .
\end{aligned}
$$

In accordance with Kovalenko et al. [25], the tensile strength approaches to the maximal value when the necking appears, expressed by:

$$
\frac{\mathrm{d} S_{\text {all }}}{\mathrm{d} \varepsilon}=0 .
$$

The calculated result of Eq. (19) is:

$$
\begin{aligned}
& X_{M} S_{M}^{*} \exp \left(\varepsilon_{M}^{*}-\varepsilon\right) \frac{\varepsilon^{\varepsilon_{M}^{*}-1}}{\varepsilon_{M}^{*} \varepsilon_{M}^{*}}\left(\varepsilon_{M}^{*}-\varepsilon\right) \\
& +X_{A} S_{A}^{*} \exp \left(\varepsilon_{A}^{*}-\varepsilon\right) \frac{\varepsilon^{\varepsilon_{A}^{*}-1}}{\varepsilon_{A}^{* \varepsilon_{A}^{*}}}\left(\varepsilon_{A}^{*}-\varepsilon\right) \\
& +X_{B} S_{B}^{*} \exp \left(\varepsilon_{B}^{*}-\varepsilon\right) \frac{\varepsilon_{B}^{\varepsilon_{B}^{*}-1}}{\varepsilon_{B}^{* \varepsilon_{B}^{*}}}\left(\varepsilon_{B}^{*}-\varepsilon\right)=0 .
\end{aligned}
$$

The current magnitude of strain $\varepsilon$ is regarded as the elongation, and expressed as $\varepsilon^{*}$, where Eq. (20) can be adjusted as:

$\varepsilon^{*}=\frac{X_{M} \beta_{M} \varepsilon_{M}^{*} \varepsilon^{*\left(\varepsilon_{M}^{*}-1\right)}+X_{A} \beta_{A} \varepsilon_{A}^{*} \varepsilon^{*\left(\varepsilon_{A}^{*}-1\right)}+X_{B} \beta_{B} \varepsilon_{B}^{*} \varepsilon^{*\left(\varepsilon_{B}^{*}-1\right)}}{X_{M} \beta_{M} \varepsilon^{*\left(\varepsilon_{M}^{*}-1\right)}+X_{A} \beta_{A} \varepsilon^{*\left(\varepsilon_{A}^{*}-1\right)}+X_{B} \beta_{B} \varepsilon^{*\left(\varepsilon_{B}^{*}-1\right)}}$,

where $\quad \beta_{M}=\frac{S_{M}^{*} \exp \left(\varepsilon_{M}^{*}\right)}{\varepsilon_{M}^{* \varepsilon_{M}^{*}}}, \beta_{A}=\frac{S_{A}^{*} \exp \left(\varepsilon_{A}^{*}\right)}{\varepsilon_{A}^{* \varepsilon_{A}^{*}}}, \beta_{B}=\frac{S_{B}^{*} \exp \left(\varepsilon_{B}^{*}\right)}{\varepsilon_{B}^{* \varepsilon_{B}^{*}}}$. Eq. (21) implies the relationship between the phase contents and the elongation $\varepsilon^{*}$. The elongation $\varepsilon^{*}$ can be calculated by Eq. (21) when the austenite content $X_{A}$, bainite content $X_{B}$ and martensite content $X_{M}$ have been determined. The single-phase mechanical properties of martensite, austenite and bainite are listed in Table 1, where the mechanical properties of martensite and austenite are obtained by Davies [26], and the mechanical properties of bainite are referred to $\mathrm{Li}$ [27].

Table 1 Mechanical properties of austenite, martensite and bainite

\begin{tabular}{lcc}
\hline Phase & Tensile strength (MPa) & $\begin{array}{l}\text { Elongation } \\
\text { (\%) }\end{array}$ \\
\hline Austenite & 640 & 60 \\
Martensite & 1550 & 6 \\
Bainite & 900 & 15 \\
\hline
\end{tabular}


Table 2 Chemical compositions (wt.\%) of the B1500HS steel

\begin{tabular}{lllllll}
\hline Material & C & Si & Mn & Al & B & S \\
\hline B1500HS & 0.24 & 0.22 & 1.30 & Mo & 0.056 & 0.0021 \\
& $\mathrm{Ni}$ & $\mathrm{Cr}$ & 0.002 & 0.02 & $\mathrm{~V}$ & 0.0012 \\
& 0.016 & 0.17 & & 0.02 & \\
\hline
\end{tabular}

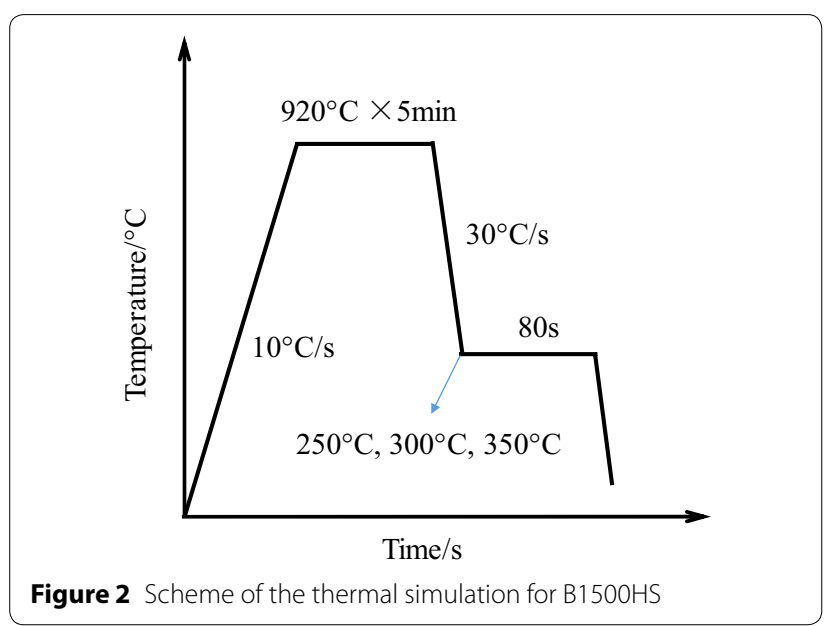

\section{Experimental Design of Q\&P Hot Stamping}

\subsection{Stamping Material}

Uncoated and cold-rolled blanks of boron steel B1500HS were used as the testing material, offered by the Bao Steel Co. The chemical compositions within the specimen are shown in Table 2, in which $1.6 \mathrm{~mm}$ is the thickness of all samples. Likewise, the original microstructure is consisted of ferrite and pearlite. The critical cooling rate of martensite transformation is $27^{\circ} \mathrm{C} / \mathrm{s}$ obtained by Tang et al. [28], and the $M_{s}$ and $M_{f}$ of B1500HS are $373{ }^{\circ} \mathrm{C}$ and $235^{\circ} \mathrm{C}$, respectively.

\subsection{Thermal Simulation Scheme}

Gleeble 3500 thermomechanical simulator was operated to simulate the temperature changing during the Q\&P hot stamping process. The dimension of a desire sample is $150 \mathrm{~mm} \times 15 \mathrm{~mm}$. The specimens were heated to $920{ }^{\circ} \mathrm{C}$ at a heating rate of $10{ }^{\circ} \mathrm{C} / \mathrm{s}$, and being held at the temperature for $5 \mathrm{~min}$. Subsequently, hot samples would be quenched to a certain temperature $\left(250{ }^{\circ} \mathrm{C} / 300{ }^{\circ} \mathrm{C} / 350{ }^{\circ} \mathrm{C}\right)$ at a cooling rate of $30{ }^{\circ} \mathrm{C} / \mathrm{s}$, and being kept at the specified temperature for $80 \mathrm{~s}$. Finally, all samples would achieve at room temperature $20{ }^{\circ} \mathrm{C}$ at a cooling rate of $30{ }^{\circ} \mathrm{C} / \mathrm{s}$, as shown in Figure 2. Oppositely, the samples used in comparative experiment were directly cooled to room temperature at a cooling rate of $30{ }^{\circ} \mathrm{C} / \mathrm{s}$ after completion of austenite transition.
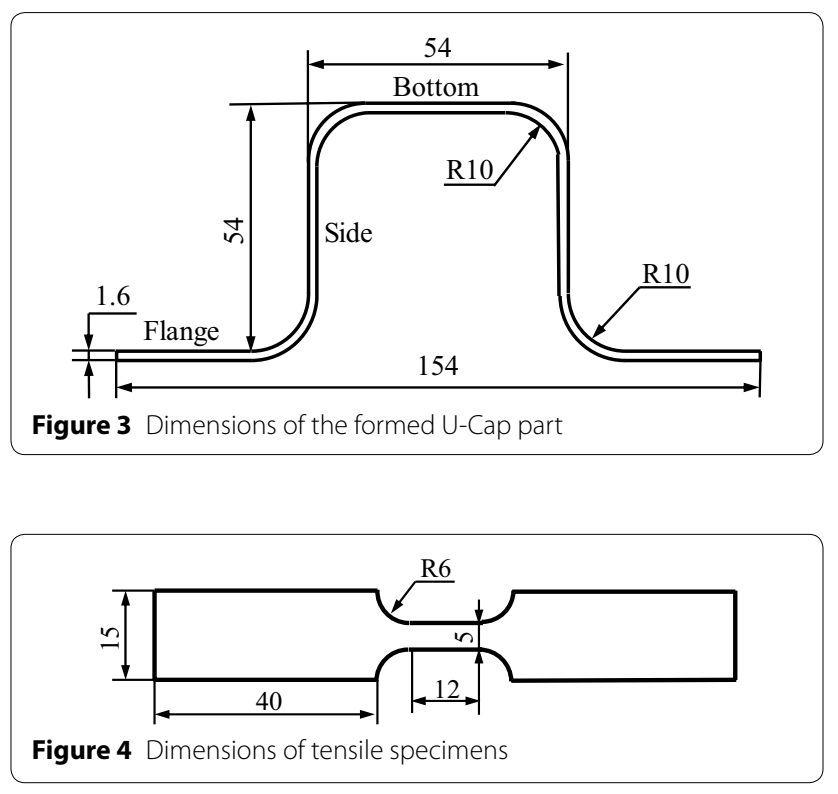

\subsection{Q\&P Hot Stamping Scheme of a U-cap Part}

In order to verify the applicability of the integrated model proposed in this paper to the actual Q\&P hot stamping process, the Q\&P hot stamping experiment of a U-cap part was carried out. The dimensions of a formed U-cap part are illustrated in Figure 3. The sheet thickness is $1.6 \mathrm{~mm}$, and the blank size is $\mathrm{L} 260 \times \mathrm{W} 150(\mathrm{~mm})$.

The sheet blank was heated up to $920^{\circ} \mathrm{C}$ in the furnace and maintained for $5 \mathrm{~min}$, then it was transferred to the tool quickly to complete the forming and quenching processes. Where a non-contact temperature measurement method by using the infrared thermal imager FLIR A615 was used to record the temperature change of the blank. After a short while, the blank was taken out from the tool at $15{ }^{\circ} \mathrm{C}$ above the carbon distribution temperature and then quickly transferred to a carbon distribution furnace, where the carbon partitioning process was conducted in the designated temperature and holding time. Finally, the specimen was taken out and secondly quenched to the room temperature for the completion of Q\&P hot stamping.

As shown in Figure 3, the flange, side and bottom of the U-cap part were taken for the following analysis. According to their contact conditions with the tool during the 
forming and quenching process, the order of the cooling rate for them is flange $>$ side $>$ bottom .

\subsection{Measurement Methods}

\subsubsection{Mechanical Properties Test}

The mechanical properties of B1500HS were obtained by tensile and hardness tests at room temperature. For Gleeble thermal simulation experiments, the temperature was distributed uniformly within a length of approximately $20 \mathrm{~mm}$. In order to generate necking and fracture in the middle of the piece during the tensile test, the gauge length of the sample was determined as $10 \mathrm{~mm}$. The shape of sample is shown in Figure 4. When sanding was completed, the specimens were performed a tensile test on a Zwick/Roell Z100 tester at a rate of $1 \mathrm{~mm} / \mathrm{min}$. Moreover, the entire procedure were repeated for three times to obtain an average value for tensile strength. Simultaneously, a little part was sheared off from the middle of the thermal simulation sample, and the measurement of hardness was carried by HVS-30P device. For the U-cap part obtained by Q\&P hot stamping, the specimens were cut from the side and flange of the U-cap part respectively for tensile and hardness testing.

\subsubsection{Optical Microstructure (OM) Observation}

The microstructure of processed samples was observed by the Image A1m metallographic microscope, in which the size was $5 \mathrm{~mm} \times 6 \mathrm{~mm}$ for all specimens. Notably, they were pre-process through a general manufacture, i.e., mechanical grinding with $\mathrm{SiC}$ sanding paper and polishing, and corroded by $4 \%$ nital for 5-6 s.

\subsubsection{Retained Austenite Content Measurement}

The content of the retained austenite was estimated by X-ray diffraction (XRD), in which Rigaku D/max$2550 \mathrm{VB} / \mathrm{PC} \mathrm{X}$-ray diffractometer was operated to support the experiment. Initially, rotating the $\mathrm{Cu}$ target with a scanning range from $35^{\circ}$ to $105^{\circ}$, and setting the unit angle to $0.02^{\circ}$. $120 \mathrm{~mA}$ was the magnitude of working current, as well as the operating voltage was $35 \mathrm{kV}$. The dimension of a specimen was $5 \mathrm{~mm} \times 6 \mathrm{~mm}$, and the oxide layer had been removed by mechanical grinding. Each set of thermal simulation process was repeated twice with individual sampling, and all samples were measured for two times for gaining the average values.

\subsubsection{Retained Bainite Content Measurement}

Bainite was detected in specimens manufactured through Q\&P hot stamping correspondingly. The mechanical properties of steel, mainly the elongation, were benefitted from certain content of bainite. Liu et al. [29] have demonstrated that bainite is a combination of ferrite +

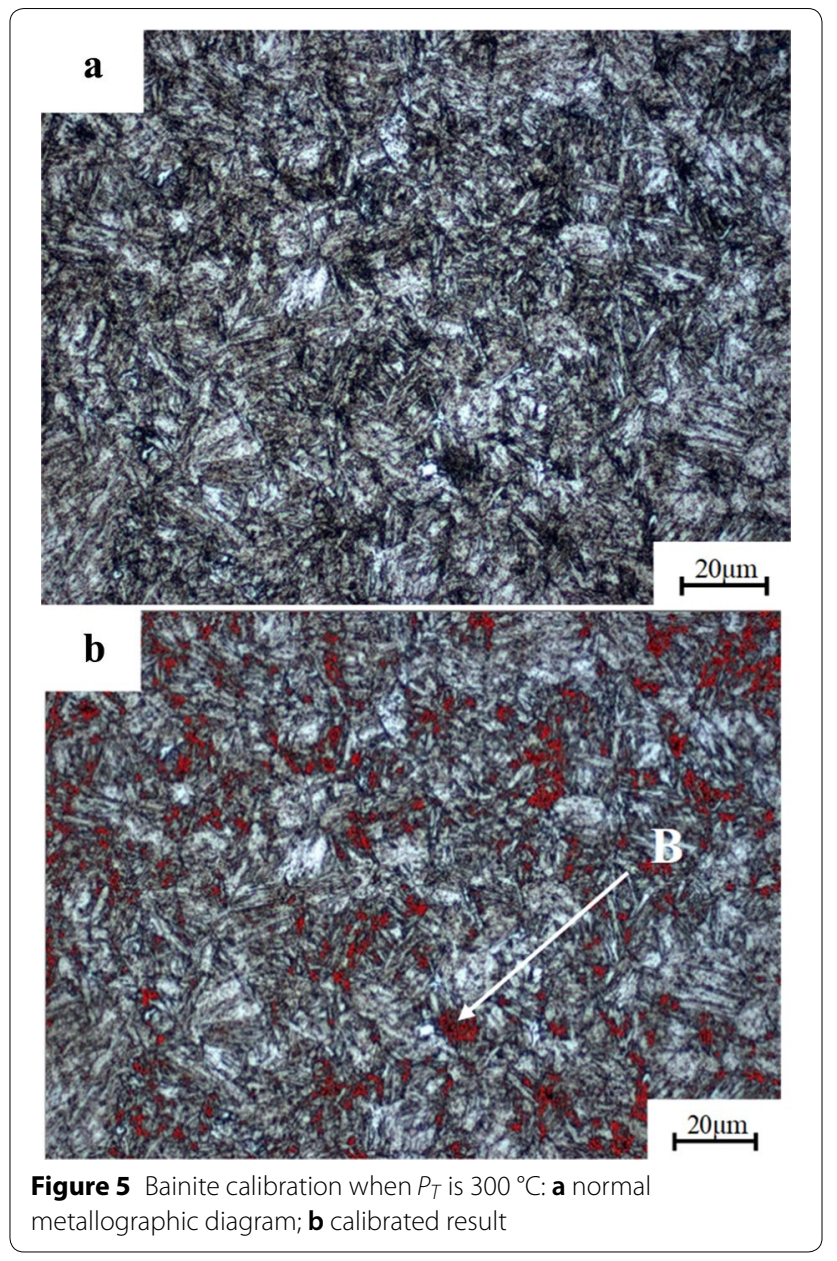

carbide, or a complex structure composed of ferrite + carbide + retained austenite. However, determining the bainite content by XRD and other inspected methods precisely is still a challenge. In accordance with the measure developed by Naderi et al. [30], the bainite is gray scaled, and the content can be obtained by Image-Pro Plus 6.0 software, which can determine the area ratio.

The calibrations of bainite at the condition of $P_{T}=300{ }^{\circ} \mathrm{C}$ are shown in Figure 5. Figure 5a) is the normal metallographic diagram of B1500HS after Q\&P hot stamping, while Figure $5 \mathrm{~b}$ ) is the calibration result, where the red area stands for bainite. Its content can be determined by the average area ratio after repeatedly calibrations.

\subsubsection{Austenite Grain Size Measurement}

A thorough procedure of measuring the original austenite grain size was carried out in order to obtain the accurate prediction results. More specifically, obtaining a piece of sample $(5 \mathrm{~mm} \times 6 \mathrm{~mm})$ from the thermal 


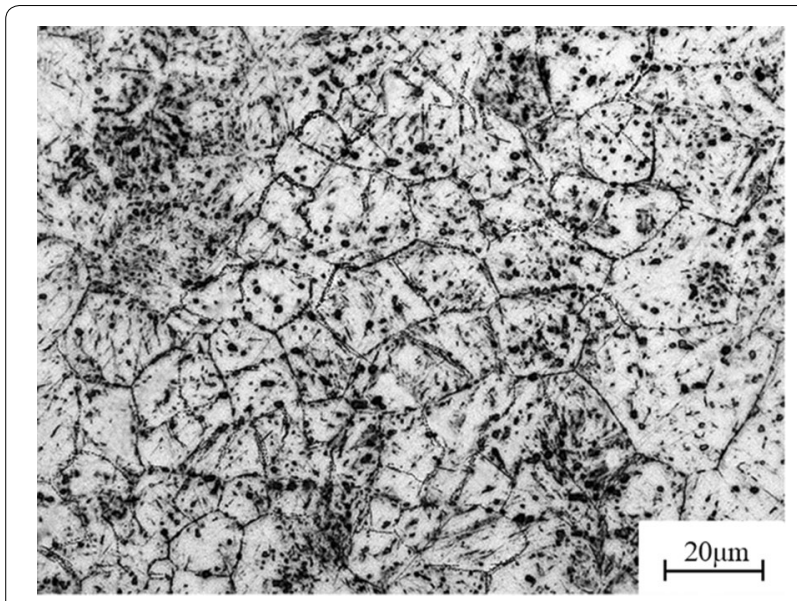

Figure 6 Image of original austenitic grain boundaries

simulation experiment, removing the decarburized layer by mechanically sanding and polishing. Afterwards, the sample was put into a corrosive solution, made by picric acid + SDBS (Sodium dodecyl benzene sulfonate) + water, at a designated temperature of $70{ }^{\circ} \mathrm{C}$. Eventually, microstructure observation was implemented by Image A1m when the original austenite grain boundary was distinct. The initial austenite grain size was determined as guided in the national standard GB/T 6394-2017. Figure 6 is the image of original austenitic grain boundaries, and the average diameter of the austenite grain is $11.2 \mu \mathrm{m}$, where $G=10$.

\section{Results and Discussion}

In this paper, the presented model was verified by Gleeble thermal simulation experiment. The data collected and generated by Gleeble simulator was accurate and reliable for the precise control of heating/cooling rate, which lead to a more convincing validation. Additionally, the combined model was utilized to predict the final properties of Q\&P hot-stamped U-cap parts based on the FEM software LS-DYNA. Afterwards, the application of the integrated model in practical manufacture case was approved by the comparison with the tested characterizations of U-cap parts as well.

\subsection{Validation of the Presented Integrated Model}

According to the Gleeble thermal simulation experiment scheme, the phase content was predicted by the presented integrated model. The original austenite grain size is selected as $G=10$ according to the measurement of the grain size in Section 3.4.

The phase content prediction results of the presented integrated model are plotted in Figure 7. When
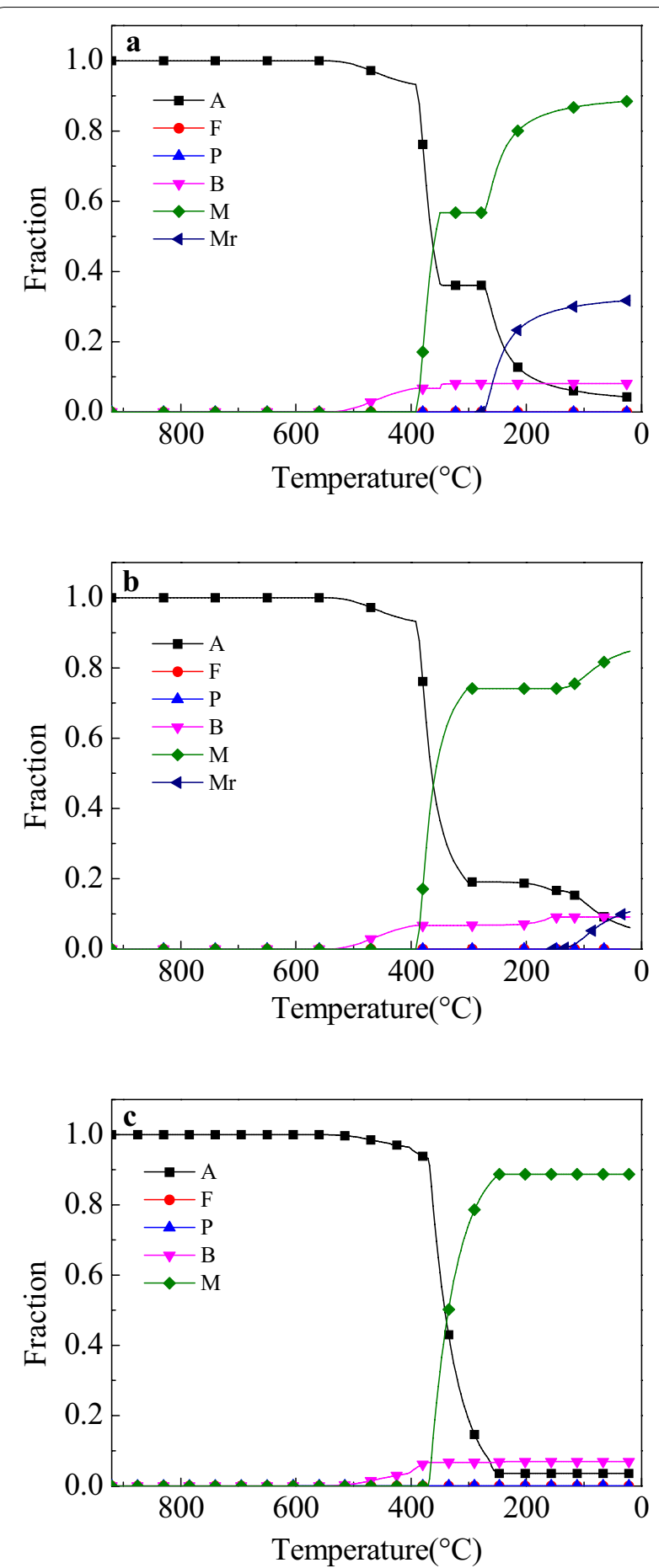

Figure 7 Phase content prediction results for Q\&P hot stamping: a $P_{T}=350^{\circ} \mathrm{C} ; \mathbf{b} P_{T}=300{ }^{\circ} \mathrm{C} ; \mathbf{c} P_{T}=250^{\circ} \mathrm{C}$ (where $\mathrm{A}$ is austenite, $\mathrm{F}$ is ferrite, $\mathrm{P}$ is pearlite, $\mathrm{B}$ is bainite, $\mathrm{M}$ is martensite and $\mathrm{Mr}$ is second martensite) 
$P_{T}$ is $350{ }^{\circ} \mathrm{C}$, the martensite content is $57.2 \%$ and the untransformed austenite content is $35.9 \%$ after the first quenching process. The carbon content in the austenite is 0.67 (wt\%) when an 80 -second duration of carbon distribution is finished. The $M_{r s}$ is $276{ }^{\circ} \mathrm{C}$, which indicates that a certain amount of secondary martensite will be formed during the second cooling process. Ultimately, the final retained austenite content is $4.2 \%$ and the martensite content is $88.9 \%$. Similarly, when $P_{T}$ is $300{ }^{\circ} \mathrm{C}$, the $M_{r s}$ is $155^{\circ} \mathrm{C}$ and the secondary martensite is formed during subsequent cooling processing, leading to $7.0 \%$ content of the final retained austenite, and $86.1 \%$ of the martensite content. The austenite content is $3.5 \%$ and the martensite content is $89.6 \%$ regarding to $250{ }^{\circ} \mathrm{C}$ as the last designated $P_{T}$. Particularly, the $M_{r s}$ point is lower than the room temperature after the carbon distribution, which illustrates the austenite can be preserved to room temperature reliably. In term of aforementioned heat treatment parameters, the ferrite and pearlite contents are situated at a degree of $10^{-5}$, which can be neglected. The final bainite contents (6.9\%) are almost identical for all three $P_{T}$, because the finalization of bainite transformation is always prior to the carbon partitioning stage.

A combined model, involving A-O, K-M, and CCE, was performed as the contrast model in this paper. The A-O model presented by Åkerström and Oldenburg [8] is a modified model based on the extensively utilized classical K-V model, considering the influence of boron in hot stamped steel, so it's usually used for the prediction of diffusional phase transformation of hot stamped boron steel. The K-M model proposed by Koistinen and Marburger [9] is the main model widely used for studying martensitic transformation at present, in which the original austenite grain size is not taken into account. Therefore, through comparing with the prediction results of the contrast model, the rationality of the present model used in this paper can be better proved.

The comparison results are illustrated in Table 3. Obviously, the predicted contents of austenite and bainite outputted by the presented model are closer to the experimental values at three carbon partition temperatures compared with the contrast model. For instance, the relative error yielded by the contrast model is $83 \%$ for the prediction of austenite when $P_{T}$ is $350{ }^{\circ} \mathrm{C}$, but only $11 \%$ for the presented model. Therefore, the accuracy of the presented model is more trustworthy and reliable than the opposite model.

The integrated model is capable to foresee the phase contents of Q\&P hot-stamped products, in which the main reasons for the conclusion are as follows:

Regarding to the prediction of martensitic transformation, K-M model considers the influences of supercooling and phase content exclusively, but the influence of austenite grain size and the carbon content in austenite are further considered in Lee model. Lee et al. [31] confirmed that the original austenite grain size has a great influence among the martensite nucleation, generation, and $M_{s}$ point. Hippchen et al. [32] obtained the phase transition curve of martensite under $\mathrm{K}-\mathrm{M}$ model and Lee model via LS-DYNA 971. The martensitic transformation curve predicted by Lee model coincides with the experimental curve, while the curve predicted by K-M model is much different from the experimental curve at lower temperatures.

Regarding to the prediction of diffusional phase transitions, i.e., bainite, ferrite, and pearlite transitions, the TTT curve within K-V model is substituted by CCT curve in Li model, because most phase transitions are performed under the condition of continuous cooling in industrial manufacture. Bok et al. [2] predicted both the phase transformation and the hardness of a hot stamped

Table 3 Comparisons of phase contents prediction results with experimental values

\begin{tabular}{|c|c|c|c|c|c|c|}
\hline \multirow[t]{2}{*}{$P_{T}\left({ }^{\circ} \mathrm{C}\right)$} & \multirow[t]{2}{*}{ Results by } & \multicolumn{2}{|l|}{ A } & \multicolumn{2}{|l|}{ B } & \multirow{2}{*}{$\begin{array}{l}\text { M } \\
\text { Cont. } \\
\text { (\%) }\end{array}$} \\
\hline & & Cont. (\%) & Err. (\%) & $\begin{array}{l}\text { Cont. } \\
\text { (\%) }\end{array}$ & Err. (\%) & \\
\hline \multirow[t]{3}{*}{250} & Experiment & 3.2 & - & 6.1 & - & - \\
\hline & Presented model & 3.5 & 9.4 & 6.9 & 13.1 & 89.6 \\
\hline & Contrast model & 3.7 & 15.6 & 4.6 & 24.6 & 91.7 \\
\hline \multirow[t]{3}{*}{300} & Experiment & 6.2 & - & 6.8 & - & - \\
\hline & Presented model & 7.0 & 12.9 & 6.9 & 1.5 & 86.1 \\
\hline & Contrast model & 10.6 & 71.0 & 4.6 & 32.3 & 84.8 \\
\hline \multirow[t]{3}{*}{350} & Experiment & 4.7 & - & 7.2 & - & - \\
\hline & Presented model & 4.2 & 10.6 & 6.9 & 4.2 & 88.9 \\
\hline & Contrast model & 0.8 & 83.0 & 4.6 & 36.1 & 94.6 \\
\hline
\end{tabular}



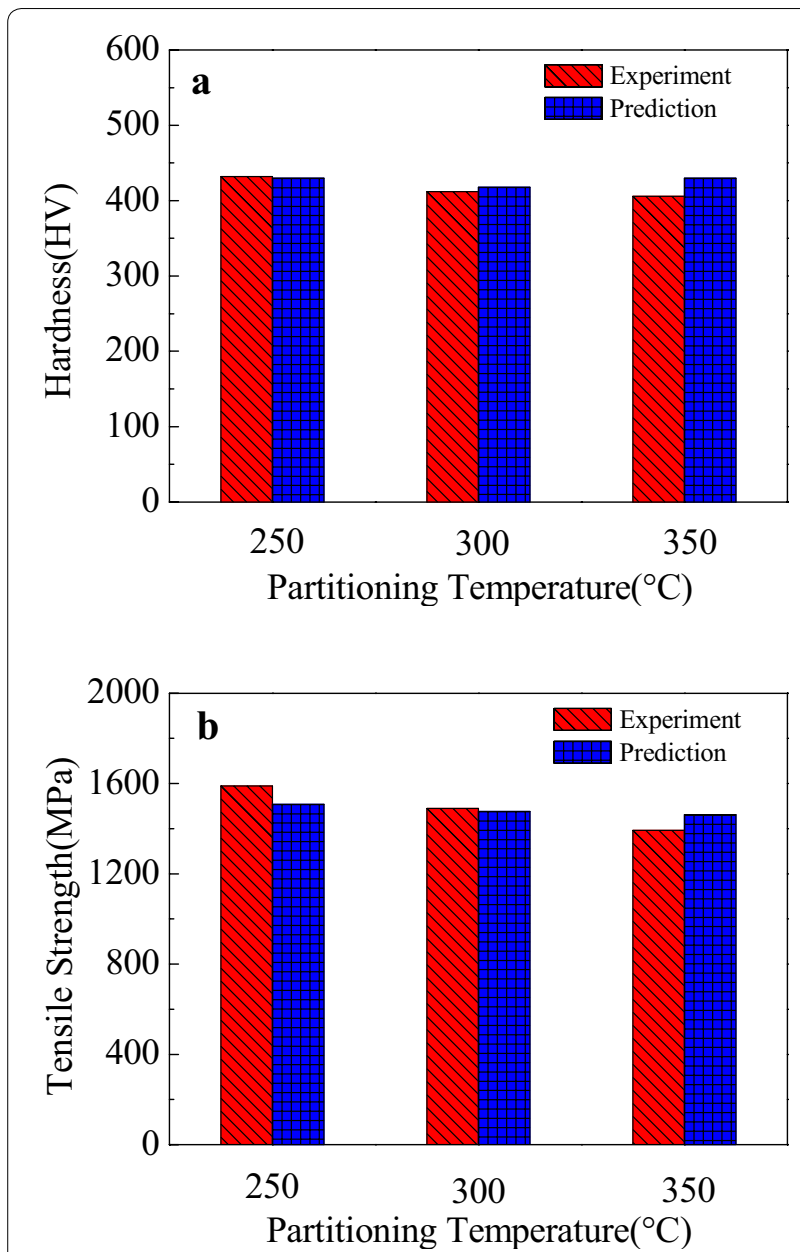

Figure 8 Comparison between predicted and experimental results for Q\&P hot stamping: $\mathbf{a}$ hardness; $\boldsymbol{b}$ tensile strength

B-pillar reinforcing part via LS-DYNA. Afterwards, the simulation results of B-pillar formation outputted by $\mathrm{K}-\mathrm{V}$ model, Li model and A-O model were compared to the experimental consequences. Eventually, the comparison exhibited that the most precise prediction of hardness is provided by Li model, which demonstrated that the $\mathrm{Li}$ model is more applicable and authentic than $\mathrm{K}-\mathrm{V}$ model and A-O model for the microstructure and mechanical properties prediction of hot stamping.

Microstructure evolution of high strength steel can be exhibited via the presented model thoroughly, so it is utilized as the fundamental way to predict the mechanical properties as well. The comparison between the predicted, and experimental results of both hardness and strength after Q\&P hot stamping is presented in Figure 8 , where the predicted consequences are similar to the experimental outputs for Q\&P hot stamping, and the relative errors are less than $5 \%$.

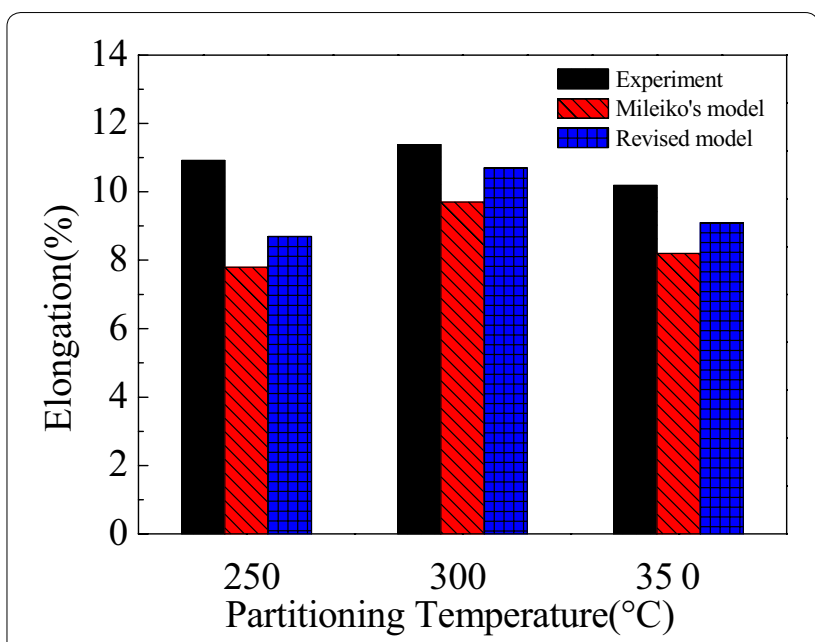

Figure 9 Comparison between predicted and experimental results of elongation

Elongation prediction is relatively arduous comparing with the hardness and strength so far. Figure 9 shows the calculated results by Mileiko's model and the revised model, as well as the experiment results. The results yielded by the modified model are more accurate at target temperatures. When $P_{T}$ is $300{ }^{\circ} \mathrm{C}$, the predicted elongation is $10.7 \%$ while the measured elongation is $11.39 \%$. Compared to the Mileiko's model, the error is decreased from $15 \%$ to $6 \%$. The predicted elongation of the revised model is $9.1 \%$, and the experimental value is $10.19 \%$ at $350{ }^{\circ} \mathrm{C}$, where the error is diminished from $19 \%$ to $10 \%$. Even though the accuracy of altered model at $250{ }^{\circ} \mathrm{C}$ is less than other temperatures, its prediction is more reasonable than the previous model.

\subsection{Model Application in A U-cap Part Properties Prediction}

The presented integrated model was implemented in the commercial FEM platform LS-DYNA, where both the diffusional and non-diffusional phase transition models including $\mathrm{Li}$ and Lee models have been involved in the material model No. 248 of the version 971. The CCE model was secondarily programmed and implemented in the platform, as well as those properties prediction models that are relied on the calculated phase contents.

To simulate the Q\&P hot stamping process, the forming and first quenching were firstly run, and the contents of martensite, ferrite, pearlite, bainite and austenite were obtained. Then, the CCE model was motivated to calculate the diffusion of carbon from martensite to austenite, and get the secondary martensite transformation temperature $M_{r s}$. If $M_{r s}$ was higher than room temperature, 


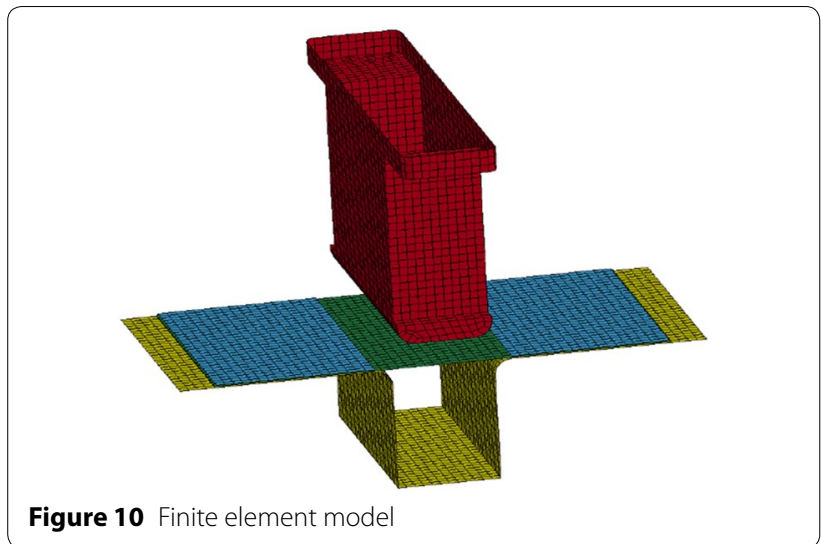

Figure 10 Finite element model

the Lee model would be activated to simulate the second martensite transformation during the quenching process. Otherwise, the unconverted austenite would be reserved to room temperature. Based on the final calculated phase contents, the hardness, strength and elongation predication models then run successively to get the mechanical properties of the part.

The effectiveness of the integrated model was examined by inspecting mechanical properties of a U-cap part outputted by the Q\&P hot stamping. Figure 10 presents the FEM model, where the shell element was used and the element quantities of the sheet, the upper tool, the blanking ring, and the lower tool are 1560, 3036, 1080 and 2880, respectively. According to the measurement, the initial temperature of the sheet and tool were set to $830{ }^{\circ} \mathrm{C}$ and $25^{\circ} \mathrm{C}$, respectively. Crucially, the determination of the heat transfer coefficient (HTC) between the tool and the blank is compulsory for further temperature calculation, a theoretical model of HTC proposed by Han et al. [33] was applied in this paper.

The microstructure evolution process of the U-cap part is shown in Figure 11, where only side part is provided as an example and the details are given in Tables 4 and 5 .

Table 4 and Table 5 illustrate the results of prediction and experiment of side and flange section, respectively. The prediction model is not appropriate for bottom section due to relatively slow cooling rate, i.e., when the side drops to the carbon partitioning temperature, the martensite transformation has not started at the bottom.

The predicted strength of the side is similar to the experimental data, e.g., the deviation is only 5-8 $\mathrm{MPa}$ at $250{ }^{\circ} \mathrm{C}$ and $300{ }^{\circ} \mathrm{C}$. When $P_{T}$ is $350{ }^{\circ} \mathrm{C}$, the experimental and predicted tensile strength are $1448 \mathrm{MPa}, 1499 \mathrm{MPa}$, individually, in which the relative error is $3.5 \%$. Regarding to flange part, the predicted tensile strength is slightly different from the experimental result at $250^{\circ} \mathrm{C}$, in which the relative error is $3.6 \%$. At either $300{ }^{\circ} \mathrm{C}$ or $350{ }^{\circ} \mathrm{C}$,
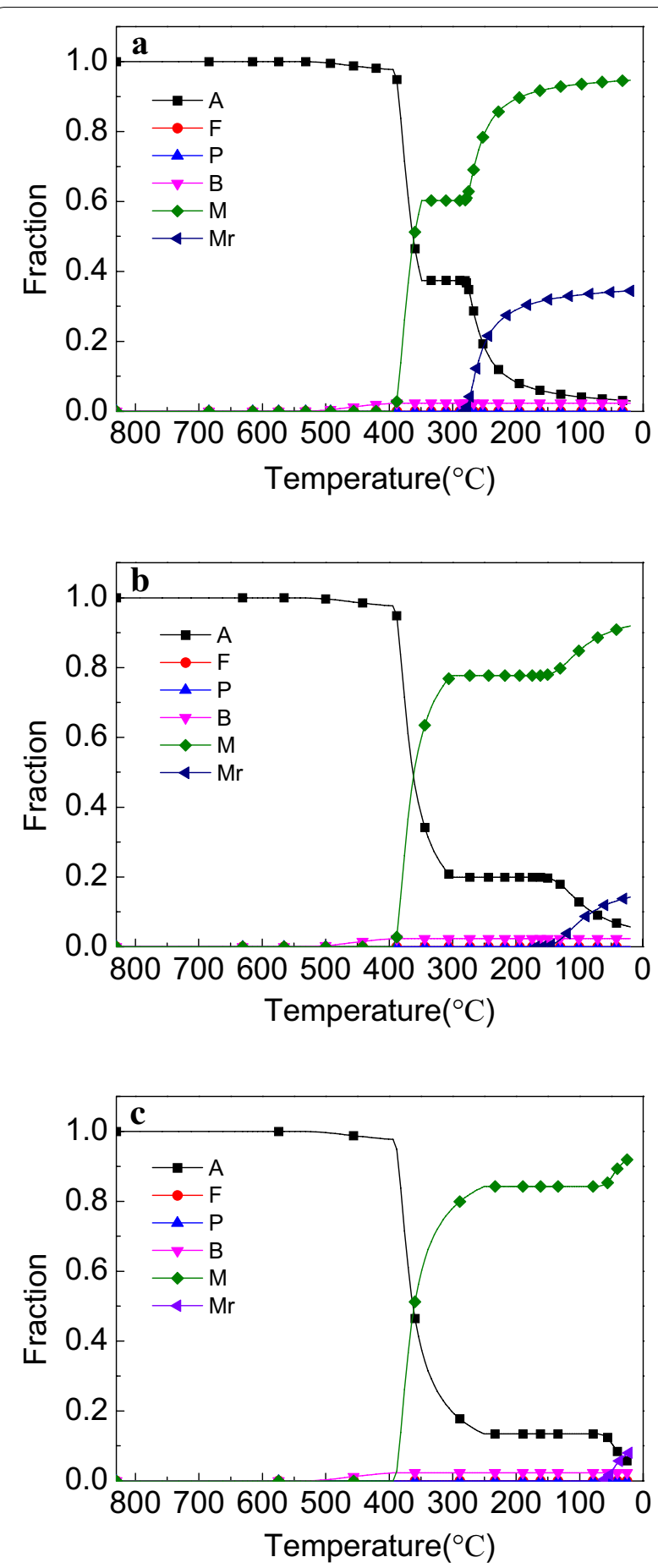

Figure 11 Microstructure evolution process of the side of U-cap part: $\mathbf{a} P_{T}=350^{\circ} \mathrm{C} ; \mathbf{b} P_{T}=300^{\circ} \mathrm{C} ; \mathbf{c} P_{T}=250^{\circ} \mathrm{C}$

the predicted and experimental values are relatively consistent.

The predicted elongation values approximately coincide with the experimental results when $P_{T}$ is $250{ }^{\circ} \mathrm{C}$. 
Table 4 Comparison between experimental and calculated phase fraction and mechanical properties for the side of a U-cap part

\begin{tabular}{|c|c|c|c|c|c|c|c|c|c|}
\hline \multirow[t]{2}{*}{$P_{T}\left({ }^{\circ} \mathrm{C}\right)$} & \multicolumn{3}{|c|}{ Phase fraction (\%) } & \multicolumn{3}{|c|}{$\sigma_{b}(\mathrm{MPa})$} & \multicolumn{3}{|l|}{$\delta(\%)$} \\
\hline & A & B & $M$ & Exp. & Cal. & Err. (\%) & Exp. & Cal. & Err. (\%) \\
\hline 250 & 5.2 & 2.3 & 92.5 & 1478 & 1483 & 0.3 & 8.7 & 8.9 & 2.3 \\
\hline 300 & 5.7 & 2.3 & 92.0 & 1461 & 1469 & 0.5 & 10.6 & 9.2 & 13.2 \\
\hline 350 & 3.1 & 2.3 & 94.6 & 1448 & 1499 & 3.5 & 9.4 & 7.7 & 18 \\
\hline
\end{tabular}

Table 5 Comparison between experimental and calculated phase fraction and mechanical properties for the flange of a U-cap part

\begin{tabular}{|c|c|c|c|c|c|c|c|c|c|}
\hline \multirow[t]{2}{*}{$P_{T}\left({ }^{\circ} \mathrm{C}\right)$} & \multicolumn{3}{|c|}{ Phase fraction (\%) } & \multicolumn{3}{|c|}{$\sigma_{b}(\mathrm{MPa})$} & \multicolumn{3}{|l|}{$\delta(\%)$} \\
\hline & A & B & M & Exp. & Cal. & Err. (\%) & Exp. & Cal. & Err. (\%) \\
\hline 250 & 6.4 & 0.4 & 93.2 & 1547 & 1491 & 3.6 & 9.4 & 9.5 & 1.1 \\
\hline 300 & 6.9 & 0.4 & 92.7 & 1474 & 1489 & 1.0 & 10.7 & 9.8 & 8.4 \\
\hline 350 & 7.6 & 0.4 & 92.0 & 1476 & 1478 & 0.1 & 11.1 & 10.2 & 8.1 \\
\hline
\end{tabular}
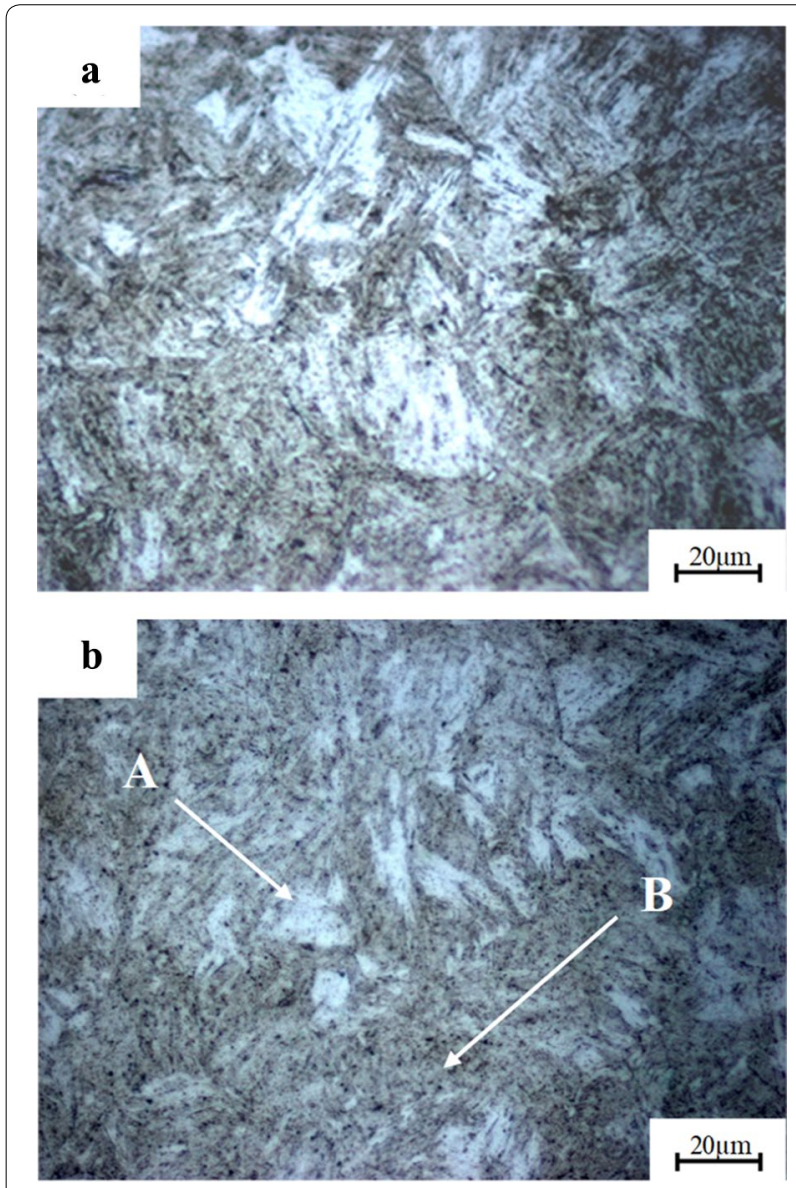

Figure 12 Microstructure of a U-cap part after Q\&P hot stamping: a flange; $\boldsymbol{b}$ side
While the predicted elongations are a little lower than the corresponding experimental results when $P_{T}$ are $300{ }^{\circ} \mathrm{C}$ and $350{ }^{\circ} \mathrm{C}$. The reasonable explanation could be that the grain has been refined during the forming and quenching process, resulted in higher real elongation than the predicted value.

Figure 12 illustrates the microstructures of flange and side after Q\&P hot stamping when $P_{T}$ is $300{ }^{\circ} \mathrm{C}$. Both parts fill with lath martensite, while more austenite can be found in the flange, which is consistent with the phase content prediction results presented in Table 4 and Table 5.

\section{Conclusions}

In this investigation, an integrated model of microstructure evolution and properties prediction with high accuracy was established for the products manufactured via Q\&P hot stamping process. Their mechanical properties including hardness, strength and elongation were yielded by theoretical and empirical formulas. All aforementioned models were operated in LS-DYNA to simulate the evolution of a U-cup part during Q\&P hot stamping process as well. Finally, the prediction models of microstructure transformations and mechanical properties were approved as accurate and reliable through the comparison with experimental results. Some innovations have been explored and achieved in this study: 
(1) A general phase transformations and mechanical properties integrated model scheme for the entire procedure of Q\&P hot stamping has been established originally.

(2) The effect of the initial grain size of austenite has been concerned and involved during the phase transition simulation.

(3) A modified model with better accuracy for the prediction of elongation has been made by comprising the influence of bainite microstructure.

\section{Acknowledgements}

The authors thank Ms. Yanan Ding and Mr. Chenglong Wang for their support and previous work.

\section{Authors' Information}

Yang Chen, born in 1976, is currently a PhD candidate at School of Materials Science and Engineering, Shanghai Jiao Tong University, China. He received her master degree from Shanghai Jiao Tong University, China, in 2003. His research interest is hot stamping technology of ultra-high strength steel. Tel: +86-21-62813430.

Huizhen Zhang, born in 1996, is currently a master graduate at School of Materials Science and Engineering, Shanghai Jiao Tong University, China.

Johnston Jackie Tang, born in 1993, is currently a master candidate at School of Materials Science and Engineering, Shanghai Jiao Tong University, China.

Xianhong Han, born in 1977, is currently a professor at School of Materials Science and Engineering, Shanghai Jiao Tong University, China. His main research interests include advanced sheet metal forming technology and FEM simulation. Tel: +86-13918604955.

Zhenshan Cui, born in 1963, is currently a professor at School of Materials Science and Engineering, Shanghai Jiao Tong University, China.

\section{Authors' Contributions}

$\mathrm{YC}$ and $\mathrm{HZ}$ were in charge of the whole trial; JJT wrote part of the manuscript; $\mathrm{XH}$ and $\mathrm{ZC}$ proposed the idea and put forward suggestion for this work. All authors read and approved the final manuscript.

\section{Funding}

Supported by National Natural Science Foundation of China (Grant Nos. 51775336, U1564203), and Program of Shanghai Academic Research Leadership (Grant No. 19XD1401900).

\section{Competing Interests}

The authors declare no competing financial interests.

\section{Author Details}

1 Institute of Forming Technology \& Equipment, School of Materials Science and Engineering, Shanghai Jiao Tong University, Shanghai 200030, China.

${ }^{2}$ National Engineering Research Center of Die and Mold CAD, Shanghai Jiao Tong University, Shanghai 200030, China.

Received: 6 August 2019 Revised: 29 April 2020 Accepted: 26 May 2020 Published online: 08 June 2020

\section{References}

[1] L Q Song, H Liu, H J Du, et al. Applications and research on representative car-body part of hot stamping. Materials Science and Technology, 2014, 22(2): 49-54

[2] H H Bok, M G Lee, E J Pavlina, et al. Comparative study of the prediction of microstructure and mechanical properties for a hot-stamped B-pillar reinforcing part. International Journal of Mechanical Sciences, 2011, 53(9): 744-752.
[3] J G Speer, F C R Assuncao, D K Matlock, et al. The "quenching and partitioning" process: background and recent progress. Materials Research 2005, 8(4): 417-423.

[4] H Liu, X Lu, X Jin, et al. Enhanced mechanical properties of a hot stamped advanced high-strength steel treated by quenching and partitioning process. Scripta Materialia, 2011, 64(8): 749-752.

[5] X H Han, YY Zhong, S L Tan, et al. Microstructure and performance evaluations on Q\&P hot stamping parts of several UHSS sheet metals. Science China: Technological Sciences, 2017, 60: 1692-1701.

[6] J S Kirkaldy, D Venugopalan. Prediction of microstructure and hardenability in low alloy steels. Proceedings of the International Conference on Phase Transformation in Ferrous Alloys, 1983: 128-148.

[7] M V Li, D V Niebuhr, L L Meekisho, et al. A computational model for the prediction of steel hardenability. Metallurgical and Materials Transactions B, 1998, 29(3): 661-672.

[8] P Åkerström, M Oldenburg. Austenite decomposition during press hardening of a boron steel-Computer simulation and test. Journal of Materials Processing Technology, 2006, 174(1): 399-406.

[9] D P Koistinen, R E Marburger. A general equation prescribing the extent of the austenite-martensite transformation in pure iron-carbon alloys and plain carbon steels. Acta Metallurgica, 1959, 7(1): 59-60.

[10] S J Lee, Y K Lee, S J Lee. Erratum to "Finite element simulation of quench distortion in a low alloy steel incorporating transformation kinetics"[Acta Mater 2008;56:1482-90]. Acta Materialia, 2009, 57(8): $1482-1490$.

[11] B Zhu, Z Liu, Y Wang, et al. Application of a model for quenching and partitioning in hot stamping of high-strength steel. Metallurgical and Materials Transactions A, 2018, 49(4): 1304-1312.

[12] Z Wang, K Wang, Y Liu, et al. Multi-scale simulation for hot stamping quenching \& partitioning process of high-strength steel. Journal of Materials Processing Technology, 2019, 269: 150-162.

[13] Y Wang, H Geng, B Zhu, et al. Carbon redistribution and microstructural evolution study during two-stage quenching and partitioning process of high-strength steels by modeling. Materials (Basel), 2018, 11(11).

[14] S J Lee, E J Pavlina, C J Van Tyne. Kinetics modeling of austenite decomposition for an end-quenched 1045 steel. Materials Science and Engineering A, 2010, 527(13): 3186-3194.

[15] L J Zhu, Z W Gu, H Xu, et al. Modeling of microstructure evolution in $22 \mathrm{MnB5}$ steel during hot stamping. Journal of Iron and Steel Research International, 2014, 21(2): 197-201.

[16] C J Hamelin, O Muránsky, M C Smith, et al. Validation of a numerical model used to predict phase distribution and residual stress in ferritic steel weldments. Acta Materialia, 2014, 75(7): 1-19.

[17] W Cui, D San-Martín, E J Pedro. Towards efficient microstructural design and hardness prediction of bearing steels - An integrated experimental and numerical study. Materials and Design, 2017, 133: 464-475.

[18] Y Yogo, N Kurato, N Iwata. Investigation of hardness change for spot welded tailored blank in hot stamping using CCT and deformationCCT diagrams. Metallurgical and Materials Transactions A, 2018, 49(6): 2293-2301

[19] K Mori, P F Bariani, B A Behrens, et al. Hot stamping of ultra-high strength steel parts. CIRP Annals, 2017, 66(2): 755-777.

[20] J Speer, D K Matlock, B C De Cooman, et al. Carbon partitioning into austenite after martensite transformation. Acta Materialia, 2003, 51 (9): $2611-2622$.

[21] J Cui, C Lei, Z Xing, et al. Predictions of the mechanical properties and microstructure evolution of high strength steel in hot stamping. Journal of Materials Engineering and Performance, 2012, 21(11): 2244-2254.

[22] D K Matlock, J G Speer. Third generation of AHSS: Microstructure design concepts. In: A Haldar, S Suwas, D Bhattacharjee (Eds.) Microstructure and Texture in Steels. Springer London, 2009: 185-205.

[23] S T Mileiko. The tensile strength and ductility of continuous fibre composites. Journal of Materials Science, 1969, 4(11): 974-977.

[24] A Kumar, S B Singh, K K Ray. Influence of bainite/martensite-content on the tensile properties of low carbon dual-phase steels. Materials Science and Engineering A, 2008, 474(1): 270-282.

[25] V P Kovalenko, ST Mileiko, V V Tvardovskii. A model of failure of a composite pipe in compression. Mechanics of Composite Materials, 1989, 25(1): 103-111.

[26] R G Davies. The deformation behavior of a vanadium-strengthened dual phase steel. Metallurgical Transactions A, 1978, 9(1): 41-52. 
[27] H P Li. Research on the constitutive relationship of hot stamping boron steel B1500HS at high temperature. Journal of Mechanical Engineering, 2012, 48(8): 21. (in Chinese)

[28] B Tang, Q Wang, Z Wang, et al. The influence of deformation history on microstructure and microhardness during the hot stamping process of boron steel B1500HS. Int. J. of Materials and Product Technology, 2013, 46(4): 255-268.

[29] Z C Liu, H Y Wang, Y F Wang, et al. Morphology and formation mechanism of bainitic carbide. Transactions of Materials and Heat Treatment 2008, (1): 32-37+46

[30] M Naderi, M Ketabchi, M Abbasi, et al. Semi-hot stamping as an improved process of hot stamping. Journal of Materials Science and Technology, 2011, 27(4): 369-376.
[31] S J Lee, Y K Lee, S J Lee. Finite element simulation of quench distortion in a low-alloy steel incorporating transformation kinetics. Acta Materialia, 2008, 56(7): 1482-1490.

[32] P Hippchen, A Lipp, H Grass, et al. Modelling kinetics of phase transformation for the indirect hot stamping process to focus on car body parts with tailored properties. Journal of Materials Processing Technology, 2016, 228(8): 59-67.

[33] X H Han, X Hao, K Yang, et al. Theoretical and experimental study of the rule for heat transfer coefficient in hot stamping of high strength steels. In: Numisheet 2014, Melbourne, Australia, 2014.

\section{Submit your manuscript to a SpringerOpen ${ }^{\circ}$ journal and benefit from:}

- Convenient online submission

- Rigorous peer review

- Open access: articles freely available online

- High visibility within the field

Retaining the copyright to your article

Submit your next manuscript at $\boldsymbol{\nabla}$ springeropen.com 